\title{
BMJ Open HIV prevalence among men who have sex with men following the implementation of the HIV preventive guideline in Tanzania: respondent- driven sampling survey
}

\author{
Mwijage Alexander Ishungisa (1D , ${ }^{1,2}$ Kare Moen, ${ }^{3}$ Germana Leyna, ${ }^{4}$ \\ Neema Makyao, ${ }^{5}$ Angela Ramadhan, ${ }^{6}$ Theis Lange, ${ }^{7}$ Dan Wolf Meyrowitsch, ${ }^{8}$ \\ Mucho Mizinduko, ${ }^{9}$ Samuel Likindikoki, ${ }^{10}$ Melkzedeck Leshabari, ${ }^{11}$ \\ Elia John Mmbaga ${ }^{12,13}$
}

To cite: Alexander Ishungisa $M$, Moen K, Leyna G, et al. HIV prevalence among men who have sex with men following the implementation of the HIV preventive guideline in Tanzania: respondent-driven sampling survey. BMJ Open 2020;10:e036460. doi:10.1136/ bmjopen-2019-036460

- Prepublication history for this paper is available online. To view these files, please visit the journal online (http://dx.doi org/10.1136/bmjopen-2019036460).

Received 18 December 2019 Revised 21 July 2020 Accepted 24 August 2020

\section{Check for updates}

(C) Author(s) (or their employer(s)) 2020. Re-use permitted under CC BY-NC. No commercial re-use. See rights and permissions. Published by BMJ.

For numbered affiliations see end of article.

\section{Correspondence to}

Mwijage Alexander Ishungisa; mwijagealexander2014@yahoo. com

\section{ABSTRACT}

Objectives To estimate HIV prevalence and associated risk factors among men who have sex with men (MSM) in Dar es Salaam, Tanzania following the implementation of the national comprehensive package of HIV interventions for key population (CHIP).

Design A cross-sectional survey using respondent-driven sampling.

Setting Dar es Salaam, Tanzania's largest city. Participants Men who occasionally or regularly have sex with another man, aged 18 years and above and living in Dar es Salaam city at least 6 months preceding the study.

Primary outcome measure HIV prevalence was the primary outcome. Independent risk factors for HIV infection were examined using weighted logistics regression modelling.

Results A total of 777 MSM with a mean age of 26 years took part in the study. The weighted HIV prevalence was 8.3\% (95\% Cl: $6.3 \%-10.9 \%)$ as compared with $22.3 \%$ (95\% Cl: $18.7 \%-26.4 \%)$ observed in a similar survey in 2014. Half of the participants had had sex with more than two partners in the month preceding the survey. Among those who had engaged in transactional sex, $80 \%$ had used a condom during last anal sex with a paying partner. Participants aged 25 and above had four times higher odds of being infected than those aged 15-19 years. HIV infection was associated with multiple sexual partnerships (adjusted OR/AOR, 3.0; 95\% Cl: 1.8-12.0), not having used condom during last sex with non-paying partner (AOR, 4.1; 95\% Cl: 1.4-7.8) and ever having engaged in group sex (AOR, 3.4; 95\% Cl: 1.7-3.6).

Conclusion HIV prevalence among MSM in Dar es Salaam has decreased by more than a half over the past 5 years, coinciding with implementation of the CHIP. It is nonetheless two times as high as that of men in the general population. To achieve the 2030 goal, behavioural change interventions and roll out of new intervention measures such as pre-exposure prophylaxis are urgently needed.

\section{Strengths and limitations of this study}

- This is the largest respondent-driven sampling survey among men who have sex with men in Tanzania and study participants were recruited from diverse strata of the population.

- The results were weighted to control for network size and clustering resulting from variations in selection probability and network sizes in respondentdriven sampling.

- Comparisons are made with HIV prevalence estimates generated in a methodologically comparable survey conducted before the launch of the national guideline for comprehensive package of HIV intervention for key population.

- Data on sexual behaviour are subject to social desirability bias.

- This study did not measure biological risk factors for HIV infection which might have provided more insight into the risk profile of this population.

\section{BACKGROUND}

Since 2004, the rate of HIV infection has been declining globally including in Tanzania. ${ }^{1}$ The Tanzania HIV Indicator and Impact Surveys indicate that the HIV prevalence among persons aged 15-49 years decreased from $7 \%$ in 2004 to $4.7 \%$ in $2016 .{ }^{23}$ The observed decrease has been attributed to concerted efforts to promote condom use and to an improved HIV testing coverage with $90.9 \%$ linkage to antiretroviral therapy (ART) among those who test positive for HIV and $87.7 \%$ viral suppression. ${ }^{2}$

While evidence of declining overall HIV infection rates has been mounting, populations at higher risk of HIV infection, such as men who have sex with men (MSM), have continued 
to carry a disproportionate burden of HIV in Africa and beyond. Studies from Africa have indicated that the HIV prevalence among MSM are 2-20 times higher than that in the general population. ${ }^{4-12}$ Recent studies have estimated the HIV prevalence among MSM in Tanzania to range from $12.5 \%$ in Zanzibar to $22.3 \%$ in Dar es Salaam and $11.1 \%$ in Tanga. ${ }^{461314}$ Practices associated with increased risk of HIV, such as multiple sexual partnerships, unprotected anal sex, group sex, alcohol and drug use, and commercial sex have been commonly reported among MSM. ${ }^{4}{ }^{1315-17} \mathrm{~A}$ high prevalence of sexually transmitted infections, such as herpes simplex virus type 2, has also been associated with high infection rates among MSM. ${ }^{4} 101215$

Populations at increased risk of HIV infection have been estimated to contribute up to $30 \%$ of new HIV infections in sub-Saharan Africa, making it impossible to leave them behind if we are to achieve the ambitious third sustainable development goal and end the HIV epidemic by $2030 .^{718}$

In 2014, Tanzania launched a national guideline for comprehensive package of HIV intervention for key population (CHIP) coupled with training of healthcare workers and the embracement of a multi-sectorial approach to control the HIV epidemic. ${ }^{19}$ CHIP provided a detailed description of preventive, curative and psychosocial interventions key population including MSM should receive when seeking healthcare services. Specifically, the guideline directed healthcare workers to provide HIV counselling and testing, screening for sexually transmitted infections, condoms, male health education, and pre-exposure and post-exposure prophylaxis as part of the preventive package. Screening for tuberculosis and other opportunistic infections, vaccination and treatment of viral hepatitis, ART and nutrition were among the treatment and care package services. Psychosocial support component of the package included mental health services, legal advice, personal development and empowerment as well as establishment of peer support groups. The roll out of CHIP alongside training of healthcare workers aimed to reduce stigma, increase service access with the ultimate goal of reduction in HIV infection rate among MSM.

Nearly half a decade later, no study has evaluated the state of the HIV epidemic in key populations. Given the notable decrease in HIV infection rates in Tanzania's general population, it is important that the dynamic of the HIV epidemic is tracked also in these populations as to inform government efforts aiming to achieve the 2030 goal. $^{2}$ This study seeks to provide information on the prevalence of HIV and associated sexual behaviour-related risk factors among MSM in Dar es Salaam following nearly half a decade of implementation of CHIP.

\section{METHODS}

\section{Design and setting}

This was a cross-sectional integrated bio-behavioural surveillance (IBBS) survey among MSM conducted between October and December 2017 in Dar es Salaam, the largest city in Tanzania. The location was chosen because it has a large population of MSM and a high prevalence of HIV, and also because baseline data were available for comparison (ie, data on HIV prevalence and associated risk factors among MSM before the implementation of the CHIP started). ${ }^{20}$ Dar es Salaam is a fast-growing city and currently has a population of about 5 million. The estimated overall HIV prevalence among adults aged $15-49$ years is $6.3 \% .^{2}$

\section{Study population}

MSM aged 18 and above were invited to participate in this survey. Participation required that the person had engaged in same-sex sex during the last 3 months preceding the survey. Also, participants needed to have had an address in, and lived in, Dar es Salaam for at least 6 months before recruitment commenced.

\section{Sample size estimation}

We used the formula by Fleiss et al to calculate the sample size which aimed at achieving desired precision around point estimates for HIV infection among MSM. ${ }^{3}$ According to the 2014 estimates for Dar es Salaam, the prevalence of HIV was $22 \%$ among MSM. ${ }^{4}$ With a desired precision of $5 \%$, taking into account a design effect (DEFF) of 3, based on the median DEFF found for key variables in similar respondent-driven sampling (RDS) surveys in the region, ${ }^{5-9}$ the estimated sample size for this study was 759 .

\section{Sampling and recruitment}

Since there was no sampling frame for MSM, eligible study participants were recruited using $\mathrm{RDS}^{21}$ RDS is a chain referral sampling method that incorporates a recruitment strategy to offset oversampling of certain population groups to minimise traditional snowballing bias. ${ }^{22}$ Initially, selected members of the target population (referred to as 'seeds') refer other members of the same population to the study team for possible participation in a succession of waves until the desired sample size is achieved. Seeds were identified from different strata of MSM among our previous study contacts and through a meeting with the key population community advisory board. Characteristics that were taken into account in selection of seeds were age, socioeconomic status, locality and sexual preference (preference for insertive or receptive anal sex). Recruitment networks and waves by age groups for this study are presented in figure 1 . To attain equilibrium, recruitment waves ranged from 5 to 14 waves depending on the seed.

\section{Data collection tool and data collection procedures}

A questionnaire validated in previous IBBS surveys conducted by our research group and others was used in this study. ${ }^{4}$ The questionnaire contained questions on sociodemographic characteristics and sexual practices and was administered in Swahili, the language spoken by all Tanzanians. Seeds were identified and represented different groups of MSM. Participants were invited to a 


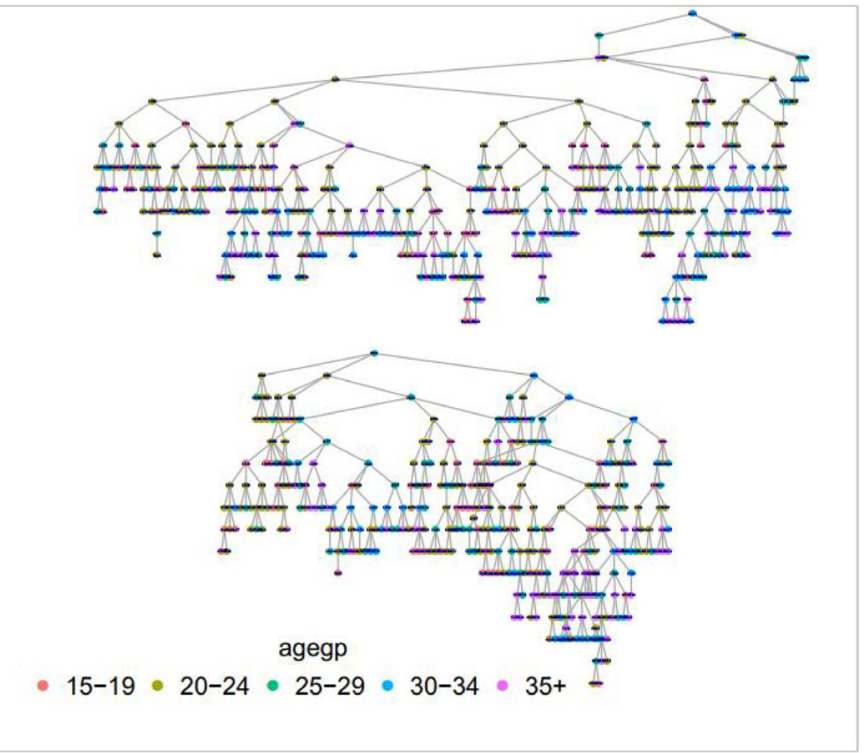

Figure 1 Recruitment networks by age groups.

recruitment centre where they were provided with information about the study and asked if they would consent to participate in it. All study participants gave informed consent to take part in the research, and face-to-face interviews using Android tablets equipped with an Open Data Kit for recording of data. Following the interviews, HIV pre-test counselling was carried out before participants were offered to test for HIV. All participants received health education and condoms after the interview and were compensated for their transportation to the study site at a rate of 8000 Tanzanian shillings (equivalent to US\$4) per person, as agreed on with MSM representatives and approved by the ethical committee of the Muhimbili University of Health and Allied Sciences. Evidence indicate that water-based lubricants are effective in HIV prevention when used during anal sexual intercourse. However, we could not provide such commodities in this study due to the fact that they were not part of HIV preventive commodities listed in the 2016 revised national guideline for CHIP of which the project abided to.

\section{Patient and public involvement}

Participants were involved in the design of the RDS, study implementation and dissemination. Results from this study were presented in the key population advisor board meeting where the study population is represented.

\section{Laboratory testing}

HIV testing followed the national testing algorithm. All samples were tested using the SD Bioline HIV-1/2 3.0 rapid test (Standard Diagnostics, Korea). Non-reactive results were considered negative for HIV, whereas reactive results were subsequently tested with Uni-Gold HIV-1/2 (Trinity Biotech, Ireland). Discrepant results were resolved by Enzygnost HIV Integral II Antibody/ Antigen ELISA (Siemens, Germany).

\section{Data analysis}

STATA V.15 and the RDSAT statistical package were used for analysis of data emanating from this survey. Data were weighted to control for network size and the clustering resulting from variations in selection probability and networks sizes. ${ }^{21}$ Categorical variables were summarised by calculating weighted proportions, and differences in proportions were examined using $\chi^{2}$ test. Median and IQR were used to summarise continuous variables. Bivariate analyses and multivariate logistic regression models were used to measure associations between various risk factors and HIV infection. All exposure variables with a $\mathrm{p} \leq 0.2$ in bivariate analysis were included into a multivariate model. Crude and adjusted OR (OR and AOR, respectively) for potential confounders with corresponding 95\% CIs are reported. All analyses were two-tailed and the significance level was set at $5 \%$.

\section{RESULTS}

During the study period, 777 eligible MSM consented to participate in the study and gave blood for HIV testing. Their overall mean age was 26.0 years $(\mathrm{SD} \pm 7.1)$ with the largest proportion (34.8\%) being 20-24 years old. A majority had competed either primary (44.8\%) or secondary $(48.4 \%)$ education. Three-quarters $(78.9 \%)$ reported to have never married, $71.1 \%$ were born and raised in Dar es Salaam and half (50.6\%) lived with their family. The median monthly income was 160000 Tanzanian shillings (IQR $80000-300000$ ), with one-third $(34.3 \%)$ reporting a monthly income above 200000 Tanzanian shillings (table 1).

\section{Sexual practices and risks}

The median age at anal sexual debut was 16 years (IQR: 14-18). Half $(51.1 \%)$ of the study participants reported to have had sex with a woman. Of those who had had sex with a non-paying male partner in the past month, more than half reported to have had either insertive $(57.3 \%)$ or receptive $(64.3 \%)$ sex with two or more partners. Use of condoms during last anal sex with a receptive nonpaying partner was reported by $9.3 \%$. Transactional sex was common among the study participants, with onethird $(32.6 \%)$ reporting to have paid another man for sex during the past month prior to the survey, and nearly three-quarters $(69.5 \%)$ reported to have sold sex in the same period. A total of $80.2 \%$ had sold sex during the 1-year period preceding the survey. While the proportion of participants who had used condoms with paid partners in the past month was $28.7 \%$, condom use with paying partners in the past month was as high as $80.0 \%$. About $15 \%$ of participants reported to have experienced condom breakage while having anal sex during the past month. Just above a quarter (26.2\%) said they had engaged in group sex at least once in their lifetime (table 2). 
Table 1 Comparison of HIV prevalence by sociodemographic characteristics among MSM in Dar es Salaam, Tanzania $(\mathrm{N}=777)$

\begin{tabular}{|c|c|c|c|c|}
\hline Variable & Category & n (\%) & $\begin{array}{l}\text { HIV positive } \\
\text { n (\%) }\end{array}$ & $P$ value \\
\hline \multirow{5}{*}{$\begin{array}{l}\text { Age } \\
\text { groups } \\
\text { (years) }\end{array}$} & $15-19$ & 134 (17.3) & $6(4.45)$ & \multirow[t]{5}{*}{0.004} \\
\hline & $20-24$ & 271 (34.8) & 28 (10.3) & \\
\hline & $25-29$ & 152 (19.6) & 24 (15.8) & \\
\hline & 30-34 & 105 (13.5) & 18 (17.0) & \\
\hline & $\geq 35$ & 115 (14.8) & $20(17.4)$ & \\
\hline \multirow{4}{*}{$\begin{array}{l}\text { Education } \\
\text { level }\end{array}$} & No formal & $21(2.7)$ & 3 (14.3) & \multirow[t]{4}{*}{0.385} \\
\hline & Primary & 348 (44.8) & 43 (12.4) & \\
\hline & Secondary & 376 (48.4) & 43 (11.4) & \\
\hline & $\begin{array}{l}\text { Above } \\
\text { secondary }\end{array}$ & $32(4.1)$ & 7 (21.9) & \\
\hline \multirow[t]{3}{*}{$\begin{array}{l}\text { Marital } \\
\text { status }\end{array}$} & $\begin{array}{l}\text { Never } \\
\text { married }\end{array}$ & 613 (78.9) & 67 (10.9) & \multirow[t]{3}{*}{0.114} \\
\hline & $\begin{array}{l}\text { Married/ } \\
\text { cohabiting }\end{array}$ & $84(10.8)$ & $14(16.7)$ & \\
\hline & $\begin{array}{l}\text { Divorced/ } \\
\text { separated }\end{array}$ & 80 (10.3) & $35(20.0)$ & \\
\hline \multirow{2}{*}{$\begin{array}{l}\text { Time lived } \\
\text { in Dar es } \\
\text { Salaam }\end{array}$} & $\begin{array}{l}\text { Born and } \\
\text { raised }\end{array}$ & 552 (71.1) & 63 (11.4) & \multirow[t]{2}{*}{0.38} \\
\hline & Not born & 225 (28.9) & 33 (14.7) & \\
\hline \multirow{4}{*}{$\begin{array}{l}\text { Income } \\
\text { past } \\
\text { month } \\
\text { (TZS) }\end{array}$} & $<50000$ & 133 (17.1) & 18 (13.5) & \multirow[t]{4}{*}{0.841} \\
\hline & $\begin{array}{l}50000- \\
120000\end{array}$ & 151 (19.4) & 20 (13.3) & \\
\hline & $\begin{array}{l}120001- \\
200000\end{array}$ & 227 (29.2) & $29(12.8)$ & \\
\hline & $>200000$ & 266 (34.3) & 29 (10.9) & \\
\hline \multirow{4}{*}{$\begin{array}{l}\text { Currently } \\
\text { living with }\end{array}$} & Alone & 304 (39.1) & 39 (12.8) & \multirow[t]{4}{*}{0.219} \\
\hline & Family & $393(50.6)$ & $42(10.7)$ & \\
\hline & Boyfriend & $50(6.4)$ & $11(22.0)$ & \\
\hline & $\begin{array}{l}\text { Wife/ } \\
\text { girlfriend }\end{array}$ & $30(3.9)$ & 4 (14.3) & \\
\hline
\end{tabular}

MSM, men who have sex with men; TZS, Tanzanian shilling.

\section{HIV prevalence}

The weighted prevalence of HIV was $8.3 \%$ (95\% CI: 6.3\%$10.9 \%)$. The prevalence increased linearly with age and was significantly higher among those who had had sex with a woman in the past year $(11.1 \%$ vs $5.5 \%, \mathrm{p}=0.023)$, among those who had used a condom with their last non-paying partner $(34.2 \%$ vs $12.0 \%, \mathrm{p}=0.002)$, among those who had not used a condom with last paying partner (13.9\% vs $7.4 \%, \mathrm{p}=0.041)$ and among those reporting condom breakage during last anal sex $(24.1 \%$ vs $7.7 \%, \mathrm{p}<0.0001)$. Having engaged in group sex was also associated with higher HIV prevalence $(13.0 \%$ vs $6.6 \%, \mathrm{p}=0.015)$.

\section{Comparison of HIV prevalence between 2014 and 2017}

In 2014, 753 MSM participated in a survey conducted by the same research group that carried out the present study.
Table 2 HIV prevalence by selected sexual behaviour characteristics among MSM in Dar es Salaam, Tanzania $(\mathrm{N}=777)$

\begin{tabular}{|c|c|c|c|c|}
\hline Variable & Category & N (\%) & $\begin{array}{l}\text { HIV positive } \\
\text { n (\%) }\end{array}$ & $P$ value \\
\hline \multirow{3}{*}{$\begin{array}{l}\text { Age at } \\
\text { first sexual } \\
\text { intercourse }\end{array}$} & $<15$ & $348(43.4)$ & $49(8.3)$ & \multirow[t]{3}{*}{0.979} \\
\hline & $16-18$ & 266 (33.9) & $29(8.0)$ & \\
\hline & $>18$ & $163(22.7)$ & $18(8.7)$ & \\
\hline \multirow{2}{*}{$\begin{array}{l}\text { Had sex with } \\
\text { a woman in } \\
\text { past } 1 \text { year }\end{array}$} & Yes & 377 (51.1) & $29(5.5)$ & \multirow[t]{2}{*}{0.023} \\
\hline & No & 400 (48.9) & 67 (11.2) & \\
\hline \multirow{2}{*}{$\begin{array}{l}\text { Bought sex } \\
\text { past } 1 \text { year }\end{array}$} & Yes & $320(37.6)$ & $41(9.6)$ & \multirow[t]{2}{*}{0.376} \\
\hline & No & $457(62.4)$ & 55 (7.5) & \\
\hline \multirow{2}{*}{$\begin{array}{l}\text { Sold sex past } \\
1 \text { year }\end{array}$} & Yes & $644(80.2)$ & $84(9.1)$ & \multirow[t]{2}{*}{0.108} \\
\hline & No & $133(19.8)$ & $12(5.0)$ & \\
\hline \multirow{2}{*}{$\begin{array}{l}\text { Number of } \\
\text { non-paying } \\
\text { insertive male } \\
\text { partners past } \\
\text { month }\end{array}$} & 1 & 109 (42.7) & $10(7.9)$ & \multirow[t]{2}{*}{0.067} \\
\hline & $\begin{array}{l}2 \text { and } \\
\text { above }\end{array}$ & $184(57.3)$ & 19 (10.3) & \\
\hline \multirow{2}{*}{$\begin{array}{l}\text { Number of } \\
\text { non-paying } \\
\text { receptive } \\
\text { male partners } \\
\text { in past month }\end{array}$} & 1 & 46 (35.7) & 12 (29.3) & \multirow[t]{2}{*}{0.489} \\
\hline & $\begin{array}{l}2 \text { and } \\
\text { above }\end{array}$ & $109(64.3)$ & 37 (33.9) & \\
\hline
\end{tabular}

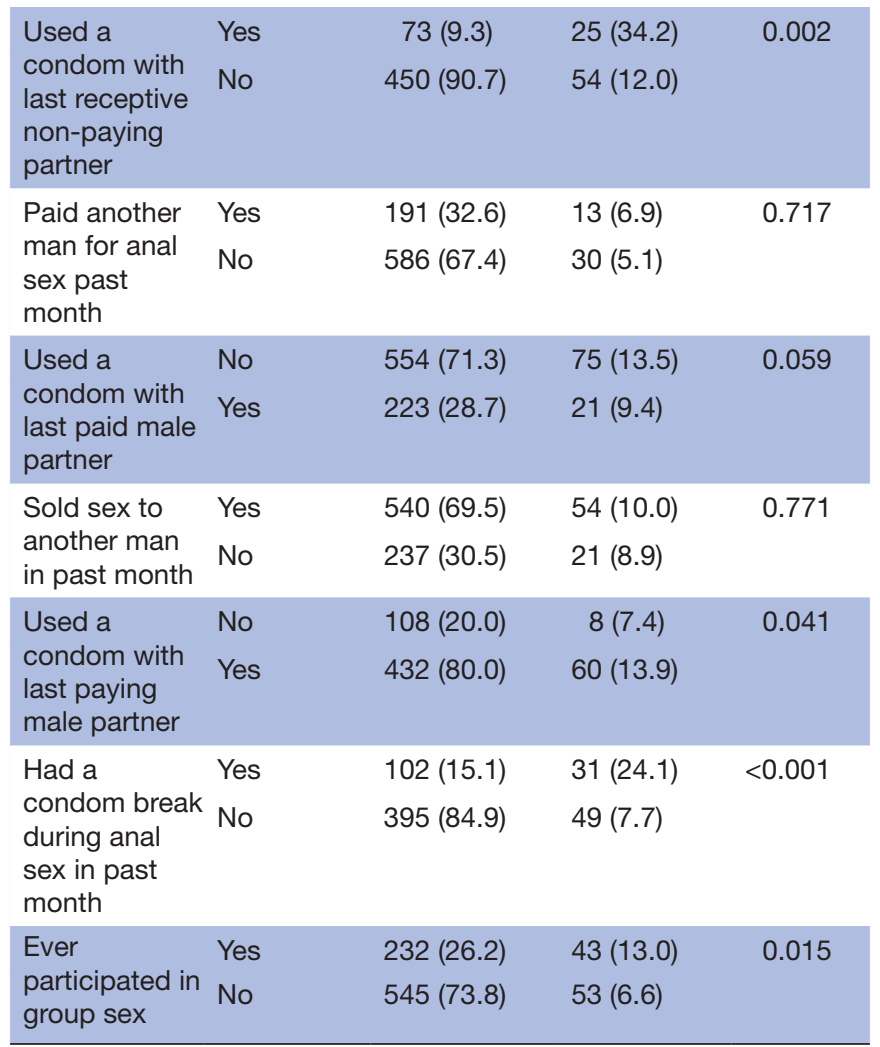

MSM, men who have sex with men.

The mean age in 2014 was 26.5 years (95\% CI: 26.1-27.1) while the mean age in 2017 was 26.0 years (95\% CI: 25.526.5). The age composition of samples therefore did not differ between the two surveys $(\mathrm{p}<0.0001)$. No significant 


\begin{tabular}{|c|c|c|}
\hline Demographic characteristic & $2014(\%)$ & $2017(\%)$ \\
\hline \multicolumn{3}{|l|}{ Age (years) } \\
\hline$\leq 24$ & 46.3 & 52.1 \\
\hline $25-34$ & 41.2 & 33.1 \\
\hline$\geq 35$ & 12.4 & 14.8 \\
\hline \multicolumn{3}{|l|}{ Level of education } \\
\hline No formal education & 1.1 & 2.7 \\
\hline $\begin{array}{l}\text { Some or completed primary } \\
\text { education }\end{array}$ & 42.9 & 44.8 \\
\hline $\begin{array}{l}\text { Some or completed secondary } \\
\text { education }\end{array}$ & 52.9 & 48.4 \\
\hline Post-secondary education & 3.1 & 4.1 \\
\hline \multicolumn{3}{|l|}{ Marital status } \\
\hline Single & 83.2 & 78.9 \\
\hline Married/cohabiting & 5.9 & 10.8 \\
\hline Separated/divorced/widower & 6.9 & 10.3 \\
\hline \multicolumn{3}{|l|}{ Current living arrangement } \\
\hline With family & 52.5 & 50.6 \\
\hline Alone & 35.3 & 39.1 \\
\hline Boyfriend & 5.7 & 6.4 \\
\hline Wife/girlfriend & 6.0 & 3.9 \\
\hline \multicolumn{3}{|l|}{ Occupation } \\
\hline Petty trader & 39.8 & 39.1 \\
\hline Employed & 17.9 & 22.4 \\
\hline Self-employed & 33.2 & 42.3 \\
\hline Other & 6.5 & 9.3 \\
\hline
\end{tabular}

statistical differences in other sociodemographic characteristics were observed between the two samples (table 3). However, the estimated HIV prevalence in 2017 was less than half that of 2014 ( $8.3 \%$ vs $22.3 \%, \mathrm{p}<0.001)$.

\section{Independent risk factors for HIV}

The results of bivariate and multivariate logistic regression of independent risk factors for HIV infection are presented in tables 4 and 5. HIV prevalence increased with age, with men aged 25 years and above having four times higher risk of infection than those who were between 15 and 19 years. Having had two or more receptive non-paying male sexual partners in the last month before the survey was associated with higher odds of HIV infection (AOR=3.0; 95\% CI: 1.8-12.0). Having used a condom during last sex with a non-paying partner was also associated with increased risk of testing positive for HIV (AOR=4.1; 95\% CI: 1.4-7.8) and those who had ever engaged in group sex had three times higher odds of being HIV positive (AOR=3.4; 95\% CI: 1.7-13.6). On the other hand, condom use during last anal sex with a paying partner (AOR=0.4, 95\% CI: 0.2-0.9) was associated with $60 \%$ lower odds of HIV infection.
Table 4 Weighted logistic regression modelling of the association between sociodemographic factors and HIV among MSM in Dar es Salaam, Tanzania

\begin{tabular}{|c|c|c|c|c|}
\hline Variable & Category & OR $(95 \% \mathrm{Cl})$ & $\begin{array}{l}\text { AOR } \\
(95 \% \mathrm{Cl})^{*}\end{array}$ & $\begin{array}{l}\mathbf{P} \\
\text { valuet }\end{array}$ \\
\hline \multirow{5}{*}{$\begin{array}{l}\text { Age groups } \\
\text { (years) }\end{array}$} & $15-19$ & 1 & 1 & \\
\hline & $20-24$ & $2.3(0.9-5.4)$ & $2.3(0.9-5.6)$ & 0.061 \\
\hline & $25-29$ & $3.5(1.5-8.4)$ & $3.9(1.6-9.5)$ & 0.003 \\
\hline & $30-34$ & $3.8(1.6-9.3)$ & $4.1(1.6-10.4)$ & 0.003 \\
\hline & $35+$ & $3.9(1.6-9.3)$ & $4.0(1.4-5.3)$ & 0.004 \\
\hline \multirow{4}{*}{$\begin{array}{l}\text { Education } \\
\text { level }\end{array}$} & No formal & 1 & & \\
\hline & Primary & $0.9(0.3-2.5)$ & & \\
\hline & Secondary & $1.8(0.3-2.4)$ & & \\
\hline & $\begin{array}{l}\text { Above } \\
\text { secondary }\end{array}$ & $1.5(0.5-5.3)$ & & \\
\hline \multirow{3}{*}{$\begin{array}{l}\text { Marital } \\
\text { status }\end{array}$} & Never married & 1 & 1 & \\
\hline & $\begin{array}{l}\text { Married/ } \\
\text { cohabiting }\end{array}$ & $0.5(0.9-1.6)$ & $1.0(0.5-2.2)$ & 0.990 \\
\hline & $\begin{array}{l}\text { Divorced/ } \\
\text { separated }\end{array}$ & $1.7(1.1-2.9)$ & $1.3(0.7-2.3)$ & 0.375 \\
\hline \multirow{3}{*}{$\begin{array}{l}\text { Time lived } \\
\text { in Dar es } \\
\text { Salaam }\end{array}$} & $\begin{array}{l}\text { Born and } \\
\text { raised }\end{array}$ & $0.4(0.1-1.1)$ & $0.4(0.1-1.3)$ & 0.117 \\
\hline & $1-5$ years & $0.6(0.2-1.0)$ & $0.6(0.2-1.3)$ & 0.386 \\
\hline & $\begin{array}{l}6 \text { and above } \\
\text { years }\end{array}$ & $0.5(0.2-1.6)$ & $0.4(0.1-1.2)$ & 0.147 \\
\hline \multirow{4}{*}{$\begin{array}{l}\text { Income } \\
\text { past month } \\
\text { (TZS) }\end{array}$} & $<50000$ & 1 & & \\
\hline & $50000-120000$ & $1.0(0.5-1.8)$ & & \\
\hline & $\begin{array}{l}121000- \\
200000\end{array}$ & $0.9(0.6-1.6)$ & & \\
\hline & $>200000$ & $0.8(0.5-1.4)$ & & \\
\hline \multirow{4}{*}{$\begin{array}{l}\text { Currently } \\
\text { living with }\end{array}$} & Alone & 1 & & \\
\hline & Family & $0.8(0.6-1.5)$ & & \\
\hline & Boyfriend & $1.7(0.9-3.1)$ & & \\
\hline & Wife/girlfriend & $1.1(0.4-2.9)$ & & \\
\hline
\end{tabular}

${ }^{*}$ Adjusted for all variables in the table with $p$ value of $\leq 0.2$ in the bivariate model.

$\dagger P$ value for adjusted $O R$.

AOR, adjusted OR; MSM, men who have sex with men; TZS, Tanzanian shilling.

\section{DISCUSSION}

This study examined HIV prevalence among MSM in Dar es Salaam after the national guideline for CHIP had been under implementation in Tanzania since 2014. The estimated HIV prevalence was $8.3 \%$ (95\% CI: $6.3 \%-10.9 \%$ ), as compared with $22.3 \%$ (95\% CI: $18.7 \%-26.4 \%$ ) in 2013. ${ }^{4}$ This observation suggests that the HIV prevalence in this population has decreased by $62 \%$ over the past 5 years. The observed decline is substantial and statistically significant. The sociodemographic characteristics of the 2014 and 2017 survey samples did not differ significantly, suggesting that differences in the study population structure may not explain the observed decline. The difference from 2014 would be even greater if our current estimates were compared with another study conducted among 
Table 5 Weighted logistic regression modelling of association between sex-related risk factors and HIV among MSM in Dar es Salaam, Tanzania

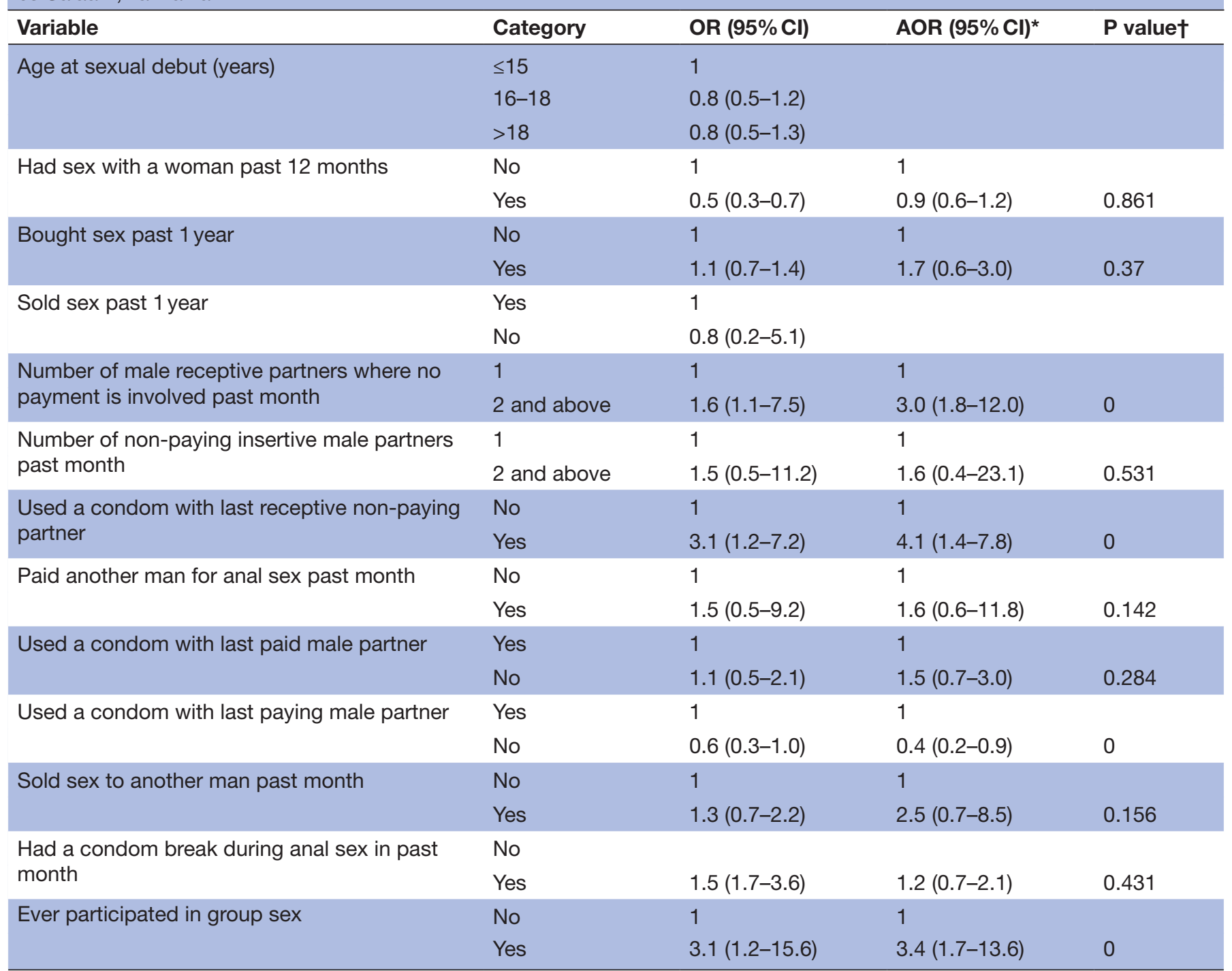

${ }^{*}$ Adjusted for all variables in the table with $p$ value of $\leq 0.2$ in the bivariate model.

$\dagger P$ value for adjusted $O R$.

AOR, adjusted OR; MSM, men who have sex with men.

MSM in Dar es Salaam that year. That study (although based on a sample of only $200 \mathrm{MSM}$ ) reported an HIV prevalence of $30.2 \%$ among MSM. ${ }^{6}$

The present survey is the first study ever to report declining HIV prevalence among MSM in Tanzania. The decline echoes the dynamic of the overall HIV situation in Tanzania, where HIV prevalence in the general population has been steadily decreasing over the past decade, from $7.0 \%$ in 2003 to $4.7 \%$ in $2016 .^{23}$ Similar trends of decreasing HIV prevalence in key population groups alongside that in the general population have also been reported elsewhere. ${ }^{7923}$

Despite the reported decrease, the HIV prevalence among MSM is still two times as high as that among men in the general population in Dar es Salaam. For this reason, recent calls for continued efforts to address HIV in highrisk populations made by the authors of a systematic review of the global epidemiology of HIV among $\mathrm{MSM}^{8}$ is still very relevant also in Dar es Salaam.

Sexual practices associated with HIV risk continue to be common among MSM in Dar es Salaam, and were significantly associated with HIV seropositivity. A substantial proportion of men have multiple sexual partnerships and engage in group sex, as has also been reported earlier both in Tanzania and elsewhere in Sub-Saharan Africa. ${ }^{45122425}$

Men aged 25 and above had higher HIV prevalence than those who were younger in this study, similar to what has been reported earlier in Dar es Salaam and elsewhere in Africa. ${ }^{41011}$ A higher HIV prevalence among older men may reflect accumulation of risk over time and/ or higher survival following ongoing efforts to improve linkage to care for people testing positive for HIV. The most recent AIDS indicator survey in Tanzania reported 
that $90.9 \%$ of persons who were between 15 and 64 years of age and who knew their HIV status indicated that they were on antiretroviral treatment, and $87.7 \%$ were virally suppressed. ${ }^{2}$ However, HIV testing coverage in the country is still low with only $52.2 \%$ of people living with HIV knowing their HIV status (in the $15-64$ age bracket). ${ }^{2}$

More than half of our study participants reported to have had sex with more than two partners. Moreover, transactional sex was very common in this population, with $64 \%$ reporting to have paid for sex during the past month, and $79 \%$ reporting to have sold sex during the last month. However, a striking finding was that condom use was very common among MSM who engaged in commercial sex. Condom use during last commercial sex was reported by a total of $80 \%$ of the study participants as compared with $49 \%$ in $2014 .{ }^{4}$ A significant increase in condom use among MSM following preventive education has recently been reported in a cohort of MSM in west Africa. ${ }^{23}$ We found that condom use with paying partners (commercial sex) was associated with a $60 \%$ lower likelihood of HIV infection in this study. This increase in protected commercial sex may partly explain the decreased HIV prevalence observed in this study.

On the other hand, condom use with regular (nonpaying) partners was low in this study (9.3\%), but comparable to that found in other studies of key populations in Tanzania. ${ }^{26}$ Low perceived susceptibility and a sense of trusting a regular partner are factors that have been associated with condom-less sex. ${ }^{27}{ }^{28}$ Worth noting in this study is the finding that condom use with regular partners was significantly associated with HIV seropositivity. It is possible that this reflects that some HIV-positive MSM use condoms when they engage in sex to ensure the safety of their partners. This has also been reported in other studies in Asia and Africa. ${ }^{1729} 30$

As was the case in our 2014 study among MSM in Dar es Salaam, nearly one-third of the study participants reported to have engaged in group sex, ${ }^{4}$ and group sex was associated with HIV infection. This underscores the need for tailored preventive messaging addressing safer group sex in implementing the CHIP. ${ }^{218}$

The results of this study should be interpreted in light of the following limitations. First, the cross-sectional nature of the survey limits causal inference of the risk factors for HIV infection identified. However, most of the risk factors reported have also been studied and reported in welldesigned longitudinal studies. Second, participants were recruited using RDS methodology which is not a random sampling methodology. Despite the fact that we used special statistical software (RDSAT) and controlled for network sizes during analysis, we acknowledge the potential for bias. Third, we collected sensitive sexual behaviour data which are subject to desirability bias. The design of the questionnaire, interviewers' training, privacy setting of interview venues and establishment of good rapport with participants were put in place to reduce desirability reporting. And fourth, we have attributed the observed decrease in HIV prevalence to the implementation of the national guideline for CHIP based on the before and after design consideration. We acknowledge that the 2014 and the current survey of 2017 were not designed to assess the effectiveness of CHIP implementation and our conclusion may be confounded by many factors.

On the other hand, this survey was the largest MSM survey in Tanzania and Africa at large and included seeds from various MSM strata (demographic and sexual characteristics) with potentially high external validity of the results presented.

\section{CONCLUSION}

The HIV prevalence among MSM in Dar es Salaam has decreased by more than half over the past 5 years, coinciding with the implementation of the CHIP in Tanzania. Despite the considerable decrease, the HIV prevalence in this population still remains two times as high as that among men in general. More condom-protected anal sex could have played a role in the declining HIV prevalence among MSM. Efforts to promote safer sex among men who engage in multiple sexual partnerships and group sex are called for. The roll out of new intervention measures, such as pre-exposure prophylaxis, could significantly contribute in the ongoing efforts to end the epidemic.

\section{Author affiliations}

${ }^{1}$ Behavioral Sciences, Muhimbili University of Health and Allied Sciences, Dar es Salaam, United Republic of Tanzania

${ }^{2}$ Medical Botany, Plant Breeding and Agronomy, Muhimbili University of Health and Allied Sciences, Dar es Salaam, United Republic of Tanzania

${ }^{3}$ Department of Community Medicine and Global Health, University of Oslo, Oslo, Norway

${ }^{4}$ Public Health and Social Sciences, Muhimbili University of Health and Allied Sciences, Dar es Salaam, United Republic of Tanzania

${ }^{5}$ National AIDS Control Programme, Ministry of Health, Tanzania National AIDS Control Program, Dar es Salaam, United Republic of Tanzania

${ }^{6}$ National AIDS Control Programme, Ministry of Health, Kilimanjaro Christian Medical University College, Moshi, United Republic of Tanzania

${ }^{7}$ Section of Biostatistics, University of Copenhagen, Kobenhavns, Denmark ${ }^{8}$ Global Health Section, University of Copenhagen, Copenhagen, Denmark

${ }^{9}$ Epidemiology, Muhimbili University of Health and Allied Sciences, Dar es Salaam, United Republic of Tanzania

${ }^{10}$ Department of Sychiatry and Mental Health, Muhimbili University of Health and Allied Sciences, Dar es Salaam, United Republic of Tanzania

${ }^{11}$ Department of Behavioral Sciences, Muhimbili University College of Health Sciences, Dar es Salaam, United Republic of Tanzania

${ }^{12}$ Epidemiology and Biostatistics, Muhimbili University Health and Allied Sciences, Dar es Salaam, United Republic of Tanzania

${ }^{13}$ Community Medicine and Global Health, Universitetet i Oslo Avdeling for samfunnsmedisin, Oslo, Norway

Contributors MAl analysed data, interpreted results and drafted the manuscript. EJM designed the study, analysed data and interpreted results. KM, GL, TL, NM, AR, ML and DWM designed the study and interpreted the results. SL and MM collected data and interpreted the results. All authors revised and approved the final version of the manuscript.

Funding The work was supported by funding from Danida Fellowship Centre (DFC) through Project No. 16-P03-TAN and Global Fund to Fight AIDS, Tuberculosis, and Malaria through Tanzania National AIDS Control Programme.

Competing interests None declared. 
Patient and public involvement Patients and/or the public were involved in the design, or conduct, or reporting, or dissemination plans of this research. Refer to the Methods section for further details.

Patient consent for publication Not required.

Ethics approval The protocol for this survey was reviewed and approved by the ethical review committee of the Muhimbili University of Health and Allied Sciences (MUHAS). Permission to conduct the study was thereafter sought from local authorities. All participants provided written informed consent to participate separately for interviews and blood sample collection. Participants who tested positive for HIV were referred to care and treatment for further management.

Provenance and peer review Not commissioned; externally peer reviewed.

Data availability statement Data are available upon reasonable request.

Open access This is an open access article distributed in accordance with the Creative Commons Attribution Non Commercial (CC BY-NC 4.0) license, which permits others to distribute, remix, adapt, build upon this work non-commercially, and license their derivative works on different terms, provided the original work is properly cited, appropriate credit is given, any changes made indicated, and the use is non-commercial. See: http://creativecommons.org/licenses/by-nc/4.0/.

\section{ORCID iD}

Mwijage Alexander Ishungisa http://orcid.org/0000-0002-6810-8312

\section{REFERENCES}

1 GBD HC. Estimates of global, regional, and national incidence, prevalence, and mortality of HIV, 1980-2015: the global burden of disease study 2015. Lancet HIV 2016;3:e408.

2 NBS Statistics. Tanzania HIV impact survey 2016-2017: preliminary findings. Dar es Salaam: NBS, NACP, 2017.

3 Fleiss J, Levin B, Paik M. Statistical methods for rates and proportions. Dar es Salaam: John Wiley \& Sons, 2013.

4 Mmbaga EJ, Moen K, Leyna GH, et al. HIV prevalence and associated risk factors among men who have sex with men in Dar ES Salaam, Tanzania. J Acquir Immune Defic Syndr 2018;77:243-9.

5 Mmbaga EJ, Moen K, Makyao N, et al. HIV and STI S among men who have sex with men in Dodoma municipality, Tanzania: a crosssectional study. Sex Transm Infect 2017;93:314-9.

6 Ross MW, Nyoni J, Ahaneku HO, et al. High HIV seroprevalence, rectal STIs and risky sexual behaviour in men who have sex with men in Dar ES Salaam and Tanga, Tanzania. BMJ Open 2014;4:e006175.

7 Baral SD, Grosso A, Holland C, et al. The epidemiology of HIV among men who have sex with men in countries with generalized HIV epidemics. Curr Opin HIV AIDS 2014;9:156-67.

8 Beyrer C, Baral SD, van Griensven F, et al. Global epidemiology of HIV infection in men who have sex with men. Lancet 2012;380:367-77.

9 Djomand G, Quaye S, Sullivan PS. HIV epidemic among key populations in West Africa. Curr Opin HIV AIDS 2014;9:506-13.

10 Ferré VM, Gbeasor-Komlanvi FA, Collin G, et al. Prevalence of human papillomavirus, human immunodeficiency virus, and other sexually transmitted infections among men who have sex with men in Togo: a national cross-sectional survey. Clin Infect Dis 2019;69:1019-26.

11 Hladik W, Barker J, Ssenkusu JM, et al. Hiv infection among men who have sex with men in Kampala, Uganda--a respondent driven sampling survey. PLoS One 2012;7:e38143.

12 Ouedraogo HG, Ky-Zerbo O, Grosso A, et al. Human immunodeficiency virus (HIV) among men who have sex with men: results of the first integrated biological and behavioral survey in Burkina Faso, West Africa. BMC Public Health 2019;19:5.

13 Dahoma M, Johnston LG, Holman A, et al. HIV and related risk behavior among men who have sex with men in Zanzibar, Tanzania: results of a behavioral surveillance survey. AIDS Behav 2011;15:186-92.

14 Zanzibar AIDS Commission (ZAC) NBoSN, Office of the Chief Government Statistician (OCGS), ICF International. Tanzania HIV/ AIDS and malaria indicator survey 2011-2012. Dar es salaam, Tanzania: Zanzibar AIDS Commission (ZAC), National Bureau of Statistics (NBS), Office of the Chief Government Statistician (OCGS), ICF International, 2013.

15 Baral S, Sifakis F, Cleghorn F, et al. Elevated risk for HIV infection among men who have sex with men in low- and middle-income countries 2000-2006: a systematic review. PLoS Med 2007;4:e339.

16 Dahoma MJ SA. Abdool R: HIV and substance abuse: the dual epidemics challenging Zanzibar. African Journal of Drugs and Alcohol Studies 2006;5:129-38.

17 Merrigan M, Azeez A, Afolabi B, et al. HIV prevalence and risk behaviours among men having sex with men in Nigeria. Sex Transm Infect 2011;87:65-70.

18 UNAIDS. 90-90-90-an ambitious treatment target to help end the AIDS epidemic. Geneva, Switzerland: UNAIDS, 2014. http:// wwwunaidsorg/en/resources/

19 Programme NAC. Comprehensive guideline for HIV prevention among key population in Tanzania. Dar es Salaam, Tanzania: NACP, 2016.

20 Mmbaga EJ LG, Mpembeni R, Moen K, et al. Intergrated biobehavioral survey among men who have sex with men in Dar ES Salaam, Tanzania. Dar es Salaam, Tanzania: National AIDS Control Program, MUHAS, 2014

21 Heckathorn DD. Respondent-driven sampling II: deriving valid population estimates from Chain-Referral samples of hidden populations. Soc Probl 2002;49:11-34.

22 Heckathorn DD. Snowball versus RESPONDENT-DRIVEN sampling. Sociol Methodol 2011;41:355-66.

23 Coulaud PJ S-TL, Mimi M, Maradan G, et al. Changes in risky sexual behaviours among West African MSM enrolled in a quarterly HIV testing and counselling prevention programme. Sex Transm Infect 2019;2019.

24 Mgbako O, Park SH, Callander D, et al. Transactional sex, condomless anal sex, and HIV risk among men who have sex with men. Int J STD AIDS 2019;30:795-801.

25 Coulaud PJ S-TL, m Mimi M, M'madi Mrenda B, et al. Combined sexual behavioral profiles in HIV-seronegative men who have sex with men in West Africa. Arch Sex Behav 2019;2019.

26 Mbita GMA, Plotkin M, Casalini C, et al. Consistent condom use and dual protection among female sex workers: surveillance findings from a large-scale, community-based combination HIV prevention program in Tanzania. AIDS Behav 2019;2019.

27 Manjengwa PG, Mangold K, Musekiwa A, et al. Cognitive and behavioural determinants of multiple sexual partnerships and condom use in South Africa: results of a national survey. South Afr J HIV Med 2019;20:868.

28 Giano Z, Kavanaugh KE, Durham AR, et al. Factors associated with condom use among a sample of men who have sex with men (MSM) residing in rural Oklahoma. $J$ Homosex 2019;24:1-21.

29 Deuba K, Kohlbrenner V, Koirala S, et al. Condom use behaviour among people living with HIV: a seven-country community-based participatory research in the Asia-Pacific region. Sex Transm Infect 2018;94:200-5.

30 Tobin-West C, Nwajagu S, Maduka O, et al. Exploring the HIV-risk practices of men who have sex with men in Port Harcourt City, Nigeria. Ann Trop Med Public Health 2017;10:551. 